\title{
DESIGN OF POWER QUALITY ANALYZER BASED ON PIC MICROCONTROLLER ALONG WITH
} A COMPUTER

\author{
André Lage, Alisson Nunes, Moisés Soares Martins*, Rafael Cekiera*, Welbert Alves \\ RODRIGUES* \\ ${ }^{*}$ Universidade Federal de Ouro Preto - ICEA \\ Rua 13, $N^{o}: 115$, Loanda \\ João Monlevade, MG, Brasil
}

Emails: andrelage@hotmail.com, alisson_nunez@hotmail.com, mousis23@gmail.com, rafaeljunio@gmail.com, welbertalves@gmail.com

\begin{abstract}
This paper describes the prototype of a power quality analyzer designed for real-time measures of AC voltage, AC current, active power, reactive power, complex power, power factor, frequency, and voltage total harmonic distortion of a singlephase power system. The prototype has a PICF4550 microcontroller that works in parallel to a computer. The microcontroller collects the data from the grid and sends to the computer to show real-time graphics of voltage and current in time and frequency domain. It also shows some electrical quantities measurements in a LCD display attached on the prototype. The results of two scenarios of tests are presented and compared to a commercial power quality analyzer.
\end{abstract}

Keywords_- Power Quality Analyzer, Eletric Power Meter, PIC Microcontroller.

Resumo- Este artigo descreve um protótipo de analisador da qualidade de energia elétrica projetado para medir em tempo real tensão CA, corrente CA, potência ativa, reativa e complexa, fator de potência, frequência e distorção harmônica total da tensão de um sistema monofásico. O protótipo possui um microcontrolador PICF4550 que trabalha em paralelo a um computador. O microcontrolador coleta os dados da rede e os envia ao computador para mostrar gráficos em tempo real de tensão e corrente no domínio do tempo e da frequência. Ele também mostra algumas medições elétricas em uma tela LCD anexada ao protótipo. Os resultados de dois cenários de testes são apresentados e comparados com um analisador comercial da qualidade de energia elétrica.

Palavras-chave— Analisador da Qualidade de Energia Elétrica, Medidor de Potência Elétrica, PIC Microcontrolador.

\section{Introduction}

Currently, the demand for electricity is growing more and more due to the increase in population, economic growth, automation and other circumstances. According to a report of International Energy Agency (IEA), since 1974, except for between 2008 and 2009, global electricity production has grown continuously. For example, in 2016 the world gross electricity production increased by $2.3 \%$ in comparison to 2015 (IEA, 2018). Therefore, all resources to reduce electricity loss in order to save energy and improve the power quality are relevant.

Monitoring the quality of production electric power is a key factor to reduce electricity loss (A. A. de Oliveira Jr, 2015). There are several parameters of electrical power that describe or measure power quality, such as: voltage sags, voltage variations, interruptions, blackouts, distortion, harmonics, voltage fluctuations, total harmonic distortion (THD), and so on (Ankita A. Yeotikar, 2016; Shilpa.R, 2014). The power quality analyzer prototype, designed by the authors, is able to measure the voltage total harmonic distortion and some important electrical quantities.

The increased number of equipment that is sensitive to power disturbances is also another important reason to improve power quality (A. A. de Oliveira Jr, 2015). Nowadays there are more requirements for power quality by network utilities, customers and regulators. Usually, utilities install power quality meters at specific locations in order to record and store several power quality events for further studies (Ankita
A. Yeotikar, 2016). Finally, the advent of new power equipment, such as power-electronic converters, variable speed drives and switched mode power supplies, has brought new disturbances into the supply system (Ankita A. Yeotikar, 2016).

Hence, it has presented the importance to analyze and study power quality. This paper describes the design of a power quality analyzer by using PIC microcontroller along with a computer and some electronic components that are common to find in an electronic lab. The prototype is designed to operate in a singlephase system and it is able to measure in real-time, AC voltage, AC current, power factor (PF), active power $(\mathrm{P})$, reactive power $(\mathrm{Q})$, complex power $(\mathrm{S})$, frequency $(f)$, and voltage total harmonic distortion $\left(T H D_{v}\right)$.

\section{Energy Quality}

There are significantly different parameters to measure the disturbances that occur in a power system. In order to detect a disturbance is essentially to monitor a wide range of frequencies, magnitudes and durations of disturbances (T. Radil, 2007). In Table 1 is shown the ten most common categories of disturbances encountered in a single-phase power system.

The first sign of a power-quality problem is a distortion in the voltage waveform of the power source from a sine wave, or in the amplitude from an established references level, or a complete interruption (J. A Pomilio, 1995). The disturbance can be caused by harmonics in the current or by events in the main voltage supply system. The disturbance can go for 
a fraction of a cycle (milliseconds) to great durations (seconds to hours) in the voltage supplied by the source (Ankita A. Yeotikar, 2016; Shilpa.R, 2014).

The two major power quality disturbances are voltage sag and harmonic distortion (Ankita A. Yeotikar, 2016). Harmonic distortions are caused by nonlinear loads which can be found in industrial, commercial and domestic sectors. The following types of equipment are examples of nonlinear loads: welding machines, power-electronic converters, personal computers, copying machines, microwave oven, drill, fluorescent lamps, uninterruptible power supply, etc (Gilson Paulino, 2015).

Table 1: Categories of power quality and their typical parameters (IEEE, 1995; IEC, 2003).

\begin{tabular}{|c|c|c|c|}
\hline CATEGORY & SPECTRUM & DURATION & MAGNITUDE \\
\hline Transient & up to $5 \mathrm{MHz}$ & ns $-\mathrm{ms}$ & $0-8 \mathrm{pu}$ \\
\hline Harmonics & $0-5 \mathrm{kHz}$ & steady state & $0-0.2 \mathrm{pu}$ \\
\hline Interharmonics & $0-6 \mathrm{kHz}$ & steady state & $0-0.02 \mathrm{pu}$ \\
\hline Notching & & steady state & \\
\hline Noise & broad-band & steady state & $0-0.01 \mathrm{pu}$ \\
\hline Sag & & 0.5 cycle -1 min & $0.1-0.9 \mathrm{pu}$ \\
\hline Swell & & 0.5 cycle -1 min & $1.1-1.8 \mathrm{pu}$ \\
\hline Interruption & & $>0.5$ cycle & $<0.1 \mathrm{pu}$ \\
\hline Undervoltage & & $>1$ min & $0.8-0.9 \mathrm{pu}$ \\
\hline Overvoltage & & $>1$ min & $1.1-1.2 \mathrm{pu}$ \\
\hline
\end{tabular}

The harmonics, when circulating through the electrical grid, can cause various damages, such as: increase of the effective current in the distribution networks, overheating and vibration in rotary machines (motors and generators), heating of power cables, noise and interference in telephone lines or communication networks, malfunction of electronic devices that have rectifiers, malfunction or inefficiency of electronic devices formed by inverters, increased filament temperature of incandescent lamps, etc (IEEE, 2009).

First-order harmonics are responsible for causing harmful effects in the system since the amplitude of the harmonics decreases so fast that those with higher frequencies have a low amplitude that no longer affects the system. In general electrical installations, odd-order harmonics are more frequently encountered and with greater amplitudes, whereas even-order harmonics are more common in cases of an asymmetric signal, due to the presence of a continuous component (ANEEL, 2008). Therefore, the power quality analyzer proposed by the authors measures only oddorder harmonics up to the seventh order.

One of the main indicators of power quality is the total harmonic distortion. The $T H D \%$ indicators are the most used to quantify harmonics. These indicators ensure the quantification and analysis of harmonic effects, where the maximum tolerable level is defined by regulatory standards (Teixeira, 2009).

There are reference values for the total harmonic distortions determined by IEEE, as shown by Tables 2 and 3. These values serve for planning in terms of power quality and are established according to experimental data collection (IEEE, 2009). Voltage total harmonic distortion $\left(T H D_{v}\right)$ is given as a percentage of the fundamental voltage $\left(V_{1, r m s}\right)$ as demonstrates by equation (1), while current total harmonic distortion $\left(T H D_{i}\right)$ is given as a percentage of the fundamental current $\left(I_{1, r m s}\right)$, equation (2).

$$
\begin{aligned}
& T H D_{v}=\frac{\sqrt{\sum_{n=2}^{h m a x} V_{n, r m s}^{2}}}{V_{1, r m s}} \times 100 \\
& T H D_{i}=\frac{\sqrt{\sum_{n=2}^{h m a x} i_{n, r m s}^{2}}}{I_{1, r m s}} \times 100
\end{aligned}
$$

Table 2: Reference values for voltage total harmonic distortion (IEEE, 2009).

\begin{tabular}{|c|c|}
\hline Rated Bus Voltage $\left(V_{n}\right)$ & THD $_{v}(\%)$ \\
\hline$V_{n} \leq 1 \mathrm{kV}$ & 10 \\
\hline $1 \mathrm{kV}<V_{n} \leq 69 \mathrm{kV}$ & 8 \\
\hline $69 \mathrm{kV}<V_{n}<230 \mathrm{kV}$ & 5 \\
\hline
\end{tabular}

Table 3: Reference values for current total harmonic distortion (IEEE, 2009).

\begin{tabular}{|c|c|}
\hline$I_{S C} / I_{L}$ for $V_{n} \leq$ values of $69 \mathrm{kV}$ & $T H D_{i}(\%)$ \\
\hline$I_{S C} / I_{L}<20 \mathrm{~A}$ & 5 \\
\hline $20 \mathrm{~A} \leq I_{S C} / I_{L}<50 \mathrm{~A}$ & 8 \\
\hline $50 \mathrm{~A} \leq I_{S C} / I_{L}<100 \mathrm{~A}$ & 12 \\
\hline $100 \mathrm{~A} \leq I_{S C} / I_{L}<1000 \mathrm{~A}$ & 15 \\
\hline$I_{S C} / I_{L} \geq 1000 \mathrm{~A}$ & 20 \\
\hline
\end{tabular}

\section{Power Quality Analyzer}

As mentioned, the proposed power quality analyzer displays in real-time the values of $\mathrm{AC}$ voltage, AC current, $\mathrm{P}, \mathrm{Q}, \mathrm{S}, \mathrm{PF}, f$, and $T H D_{v}$. In order to calculate these electric quantities is necessary only to collect the data of voltage and current from the power supply. Thus, a current sensor (ACS 712-30A) is used to measure current values. This sensor works by means of the Hall effect to detect the magnetic field generated by the current passing. It generates in the output of the module (pin OUT), a proportional voltage of $66 \mathrm{mV} / \mathrm{A}$ (MicroSystems, 2017). Microchip PICF4550 microcontroller is used to collect and process current and voltage data. This microcontroller is of great applicability, low cost, and robust. It features a 16-bit RISC processor, $48 \mathrm{MHz}$ clock, Harvard architecture, $32 \mathrm{kB}$ flash memory for programs, 256 bytes of RAM for data, $2 \mathrm{kB}$ of RAM for data, and other characteristics (Microship, 2017).

The PIC microcontroller used in this project, despite the great applicability has some limitations. As it was proposed, the power quality analyzer should calculate $T H D_{v}$, which implies in analyze the voltage spectrum. Therefore, it is necessary to perform the Fourier Transform (FFT) calculation. However, 
this computation has a high computational complexity due to operations with complex numbers and recursive functions. Thus, due to the limitations of the PIC, it is decided to send the data collected by the microcontroller to a personal computer. Figure 1 shows a block diagram of the proposed power quality analyzer, it gives an idea of how the prototype along with a computer works.

A computer has more sophisticated computational tools for the analysis of signals in the frequency domain and for the printing of values and plotting curves at high level, such as the MATLAB ${ }^{\circledR}$ software.

In the MATLAB ${ }^{\circledR}$ development environment, it is able to perform the spectral analysis of the voltage and current signals collected from the Discrete Fourier Transform (DFT). Therefore, it is possible to verify the power quality by means of the parameter $T H D_{v}$ and analyze the behavior of nonlinear-loads current.

The code developed in $\mathrm{C}$ language recorded on the PIC microcontroller is coordinated to operate in conjunction with the code developed in the MATLAB $^{\circledR}$ environment. Both systems communicate via RS232/USB protocol through one of the computer communication ports and the Tx - Rx terminals of the PIC.

The PIC microcontroller also is used to perform some electric calculations and print the results on a display (16x2 LCD) attached on the prototype. This feature is useful because it does require a computer to measure the following electric quantities in real-time of a single-phase system: AC voltage, AC current, $\mathrm{P}$, $\mathrm{Q}, \mathrm{S}, \mathrm{PF}$, and $f$. Therefore, in order to calculate $T H D_{v}$ and analyze the harmonic spectrum graphically is essential to have a computer.

Hence, the PIC microcontroller has the following tasks: to carry out the collection of voltage and current data through sensors, to sample, to convert analog signals to digital, to calculate active power, reactive power, complex power, power factor and frequency, to print these calculations on a display and to send them to a computer.

In a graphical interface designed in the MATLAB $^{\circledR}$ environment is displayed the following data in real-time of a single-phase system: voltage and current graphs in time and frequency domain, AC voltage and $\mathrm{AC}$ current values, $\mathrm{P}, \mathrm{Q}, \mathrm{S}$, $\mathrm{PF}, f$, and $T H D_{v}$. Figure 7 exemplifies this graphical interface at a random scenario of test.

\section{Experimental Results}

In order to validate the power quality analyzer prototype, several test scenarios were performed varying the type of load (RC or RL), the impedance, and the applied voltage. All the values measured by the prototype were compared to a commercial power quality analyzer (Minipa ${ }^{\circledR}$ ET-5051C/ET5061C). In Table 4 , two tests scenarios are presented. The results of measurements and comparisons reported in this paper are only from the tests scenarios displayed in Table 4.

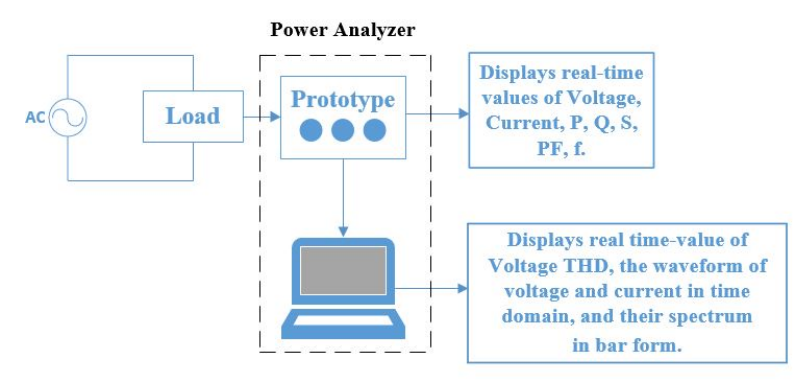

Figure 1: Block diagram of the proposed power quality analyzer.

Table 4: Description of tests scenarios.

\begin{tabular}{|c|c|c|}
\hline Scenario of Test & Type of Load & Applied Voltage \\
\hline Test 1 & $\operatorname{RC}(20-21.25 \mathrm{j}) \Omega$ & $100 \mathrm{~V}$ \\
\hline Test 2 & $\operatorname{RL}(11.62+48.8 \mathrm{j}) \Omega$ & $100 \mathrm{~V}$ \\
\hline
\end{tabular}

\subsection{Electrical Quantities Measurements Compari- son}

Figures 2 and 3 display the results of a RC (20 $-21.25 \mathrm{j}) \Omega$ load applied at $100 \mathrm{~V}$. The legend of $\mathrm{x}-$ axis of the graph in Figure 2 shows the name of some electrical quantities: voltage, complex power, active power, and reactive power. Now on the y-axis is displayed the measurement results associated with each electrical quantity. The black color represents the results from the PIC proposed analyzer, while the red color to the commercial analyzer. Note that for the voltage value the measurements are the same, however due to a small current difference, see Figure 3, the values of P, Q and S measured by the PIC proposed analyzer are different from the values of the commercial analyzer.

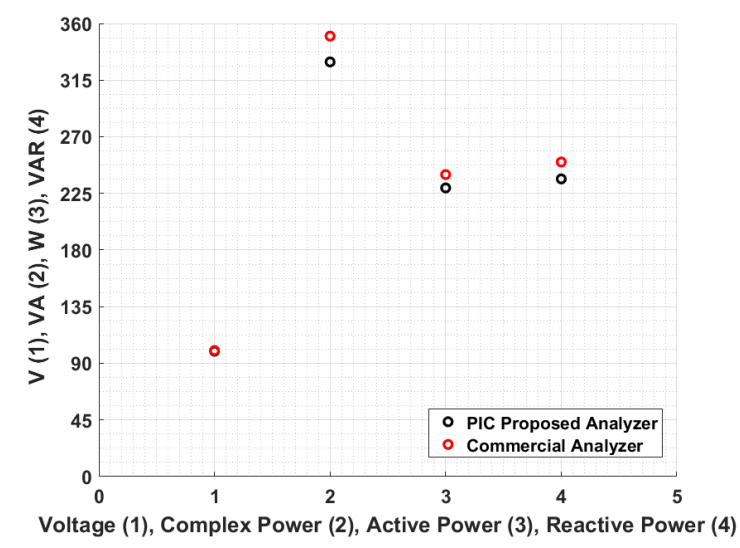

Figure 2: Electrical quantities measurement results for a RC (20 -21.25j) $\Omega$ load applied at $100 \mathrm{~V}$.

On the other hand, Figures 4 and 5 show the measured results of a RL $(11.62+48.8 \mathrm{j}) \Omega$ load applied at $100 \mathrm{~V}$. Note that, due to a small difference of current measurements, see Figure 5, the values of S, P and Q measured by the proposed analyzer are very close to 


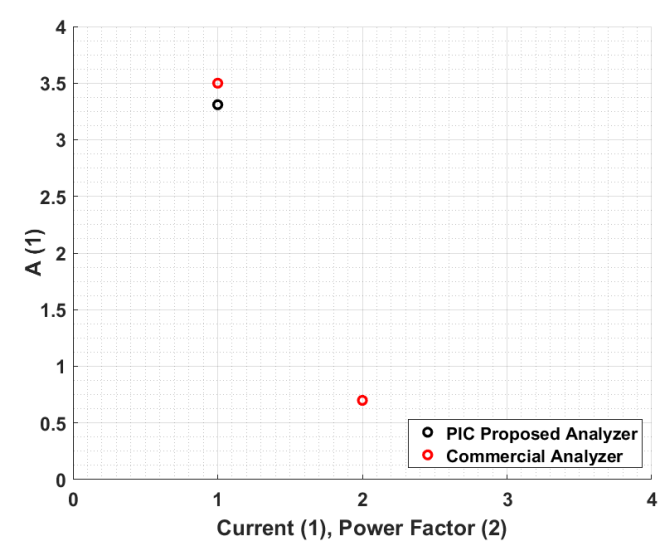

Figure 3: Electrical quantities measurement results for a RC (20-21.25j) $\Omega$ load applied at $100 \mathrm{~V}$.

the values measured by the commercial analyzer.

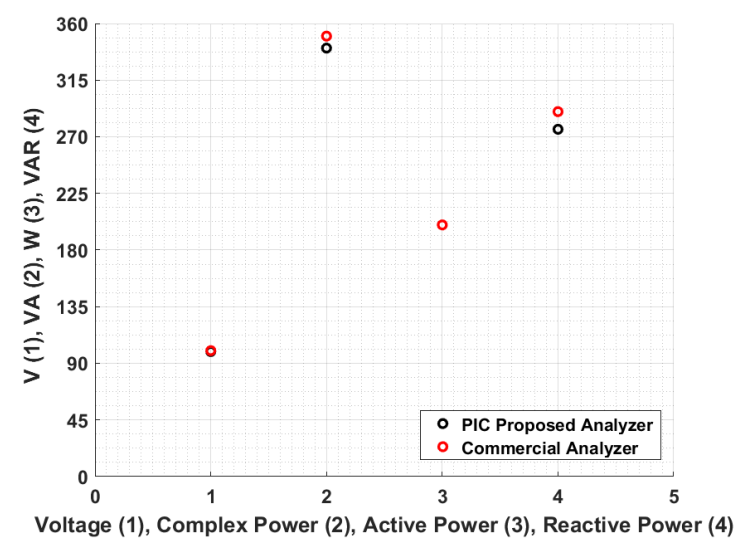

Figure 4: Electrical quantities measurement results for a RL $(11.62+48.8 \mathrm{j}) \Omega$ load applied at $100 \mathrm{~V}$.

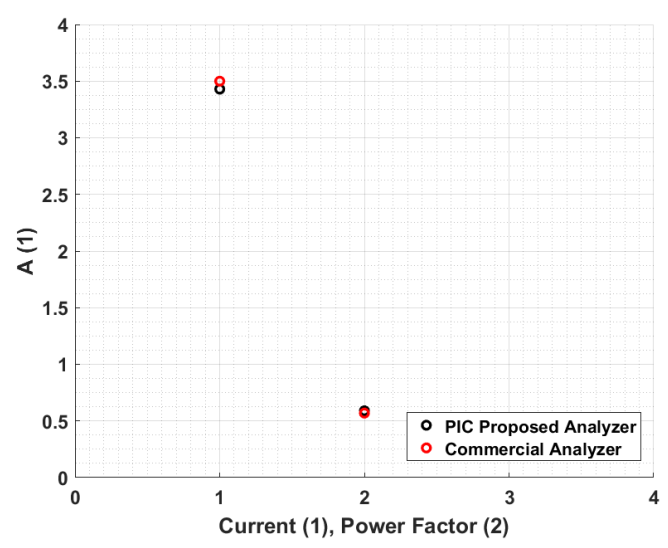

Figure 5: Electrical quantities measurement results for a $\operatorname{RL}(11.62+48.8 \mathrm{j}) \Omega$ load applied at $100 \mathrm{~V}$.

Finally, it should be noted that the values of complex power, active power, and reactive power depend on the accuracy of current and voltage measurement.
If it has a small deviation in current measurement, this error is propagated in the calculations of $\mathrm{P}, \mathrm{Q}$ and $\mathrm{S}$. This effect is observed in the results of Figure 2.

\subsection{Mean Squared Error}

Mean squared error (MSE) measures the average of the squares of the errors. It calculates the average squared difference between the estimated values (T) and what is estimated $(\theta)$, as it is demonstrated by equation (3) (Hoffmann, 2006).

$$
\operatorname{MSE}(T)=E(T-\theta)^{2}
$$

Smaller values of MSE imply smaller magnitudes of error. Figure 6 shows the mean squared error of voltage and current. Note that the levels of voltage and current in the $\mathrm{x}$-axis is increasing.
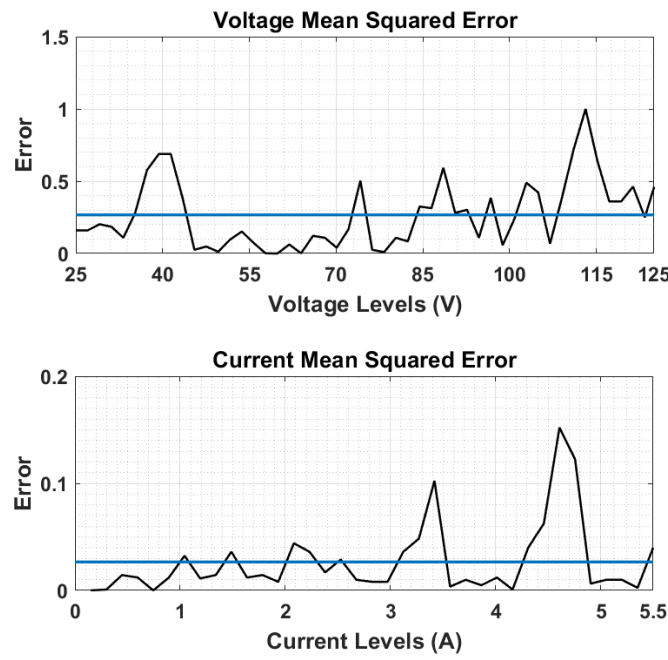

Figure 6: Voltage and current mean squared errors.

In Figure 6, is also shown the average, blue line. Note that the current MSE average is much lower compared to the voltage MSE average.

About the MSE of the voltage, voltage levels between $110 \mathrm{~V}$ to 120 present the greatest error. On the other hand, for levels of 50 to $70 \mathrm{~V}$, present the smallest error. According to the current MSE, the greatest error is in the range between 4 to $5 \mathrm{~A}$, and the lowest between 0 to $3 \mathrm{~A}$.

\subsection{An Oscilloscope Screen Simulation}

The results obtained through MATLAB ${ }^{\circledR}$ software are shown in Figure 7. In a single window, an oscilloscope screen is simulated showing, in real-time, the waveform of voltage and current in time domain, and the spectrum of voltage and current in bar form. Besides, it shows the values of RMS voltage, RMS current, complex power, active power, reactive power, power factor and the voltage total harmonic distortion. 


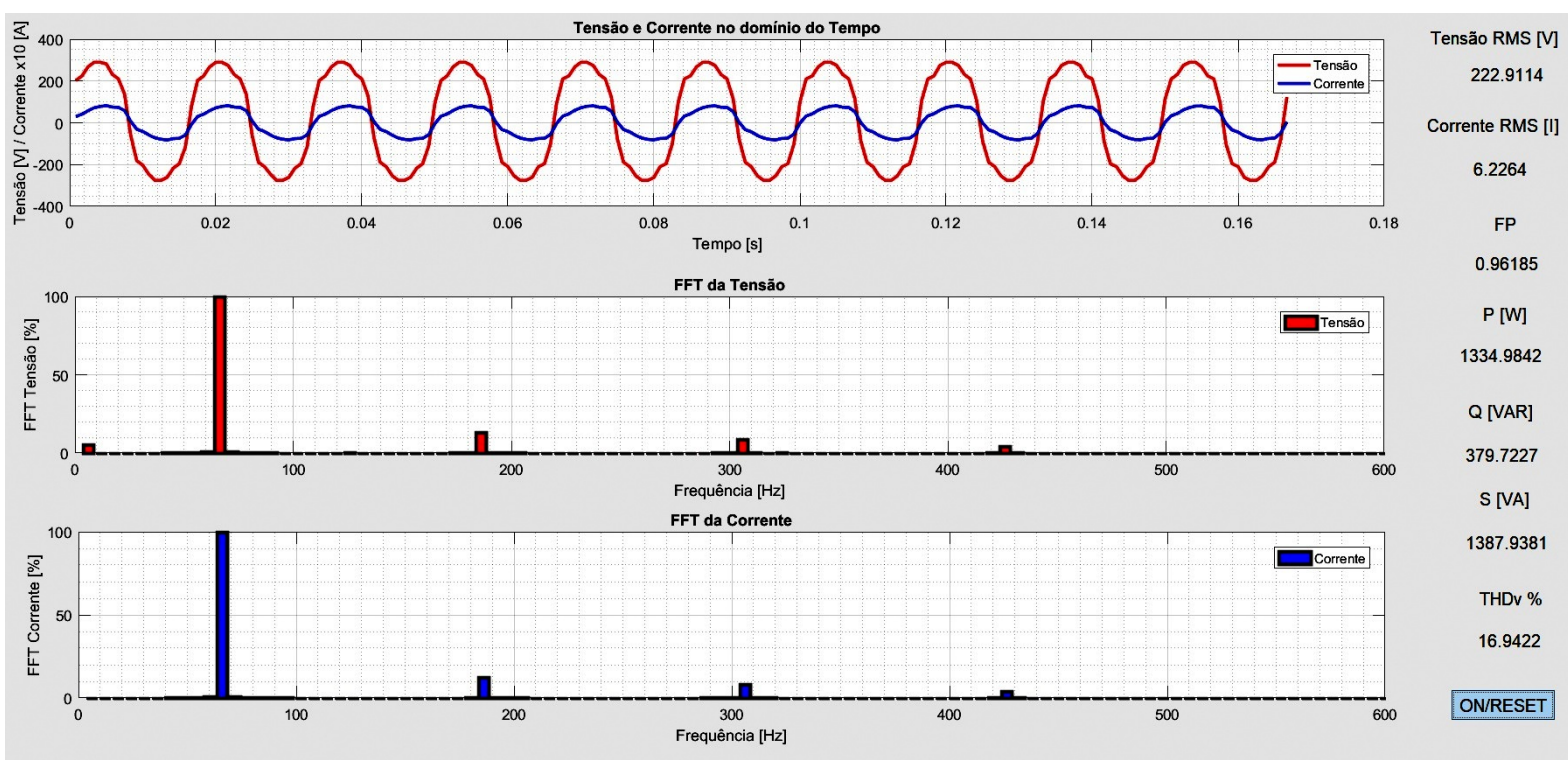

Figure 7: Graphical interface designed in the MATLAB ${ }^{\circledR}$ environment.

\section{$4.4 T H D_{v}$ Test}

For the tests with RC and RL loads, a total harmonic distortion of the voltage is not perceptible due to the linearity of these loads. Thus, a test was performed on a common half-wave rectifier circuit, i.e. with a diode and a resistor. Due to the distortion of the waveform, high values of $T H D_{v}$ were obtained, as displayed in the Table 5.

Table 5: $T H D_{v}$ Tests Results.

\begin{tabular}{|c|c|}
\hline Equipment & $T H D_{v}(\%)$ \\
\hline Commercial Analyzer & 46.7 \\
\hline PIC Proposed Analyzer & 46.1 \\
\hline
\end{tabular}

The obtained results met the expectation since the difference between the value measured by the PIC proposed analyzer and the commercial analyzer is only $0.6 \%$.

\subsection{Prototype}

Figures 8 and 9 show the final version of the PIC proposed analyzer. Observe in Figure 8 the display used to show the results of RMS voltage, RMS current, active power, complex power, reactive power, power factor, and frequency. Below the display, there are four buttons and once any of them is pressed, it shows on the display specific electrical quantities. Besides, there are three input terminals, COM (-), V (+), and $\mathrm{V}(-)$ which are used to connected the analyzer with a single-phase system in a friendly and easy way.

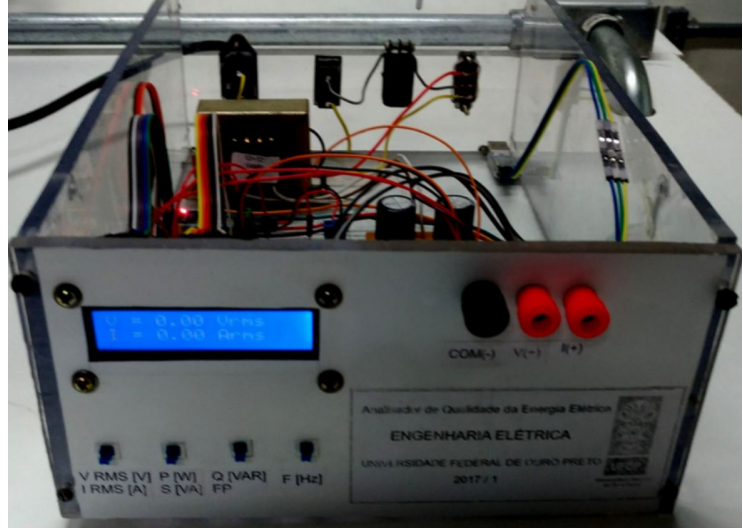

Figure 8: Front view of the PIC proposed analyzer.

\section{Conclusion}

It has discussed that analyzing power quality is quite important to many areas. As the demand for electricity is growing, monitoring power quality is essential to reduce electricity loss. Further, nowadays there is more equipment connected to the grid that is sensitive to power disturbances. Besides, the number of nonlinear loads which cause harmonic distortion is increasing lately. Therefore, this article presents a power quality analyzer based on PIC microcontroller along with a computer.

The obtained results met the expectations of this project's proposal. Analyzing Figures 2, 3, 4, 5, and 6 it can be inferred that the measurements obtained are close to a commercial analyzer. The waveforms and the $T H D_{v}$ value, shown in Figure 7, are compatible with the expectations as well. Thus, using a PIC microcontroller was able to measure correctly electrical quantities and display in real-time. Nevertheless, 


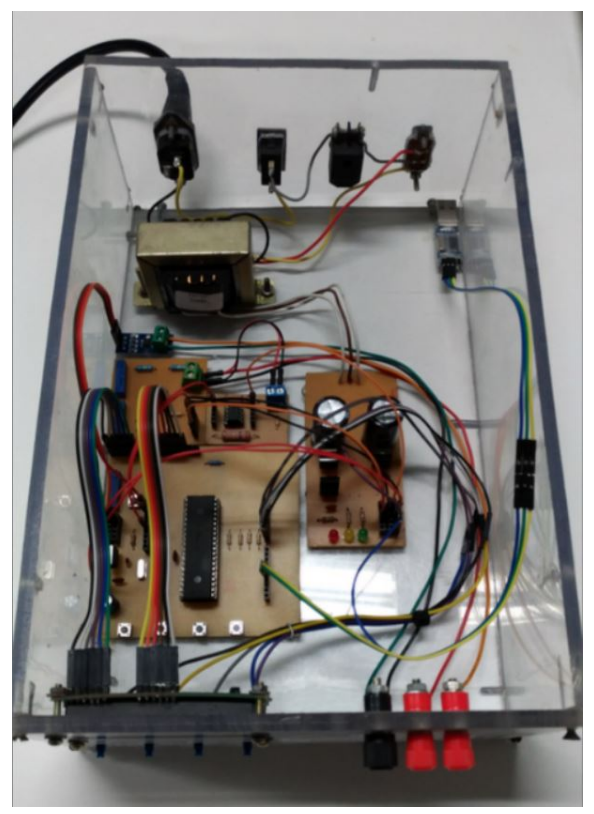

Figure 9: Top view of the PIC proposed analyzer.

it was necessary to send the data to a computer in order to compute THD and display graphics in time and frequency domain.

Future recommendations for this project concern a graphic display to plot the waveforms in real-time on the instrument itself and a microcontroller capable of performing FFT calculations, such as a digital signal processor (DSP). Also, it would be interesting to couple a battery that can be recharged by renewable sources. In this way, the instrument would become fully portable, without a computer and a power socket.

\section{Acknowledgment}

The authors would like to thank Federal University of Ouro Preto (UFOP) for providing the infrastructure to carry out this work.

\section{References}

A. A. de Oliveira Jr, R. A. Modesto, S. A. O. d. S. (2015). Study and implementation of a dual unified power quality conditioner using four-leg inverters., Eletronica de Potencia 20(3).

ANEEL (2008). Procedimentos de distribuicao de energia eletrica no sistema eletrico nacional prodist, modulo 8 qualidade da energia eletrica, Technical report, Agencia Nacional de Energia Eletrica.

Ankita A. Yeotikar, S. B. M. (2016). An overview on power quality issues in power systems, International Research Journal of Engineering and Technology - IRJET 03: 4.

Gilson Paulino, M. D. T. (2015). Variacoes de tensao de longa duracao, Revista o Setor Eletrico de Qualidade de Energia. Cap 4.
Hoffmann, R. (2006). Estatistica para Economistas, Vol. 4. Cap 9.

IEA (2018). Electricity information 2018 edtion database documentation, Technical report, International Energy Agency - IEA.

IEC (2003). Electromagnetic compatibility: Testing and measurement techniques power quality measurement methods, Technical report, International Electrotechnical Commission.

IEEE (1995). Ieee recommended practice for monitoring electric power quality, Technical report, The Institute of Electrical and electronics Engineers, Inc, New York.

IEEE (2009). Ieee recommended practice for monitoring electric power quality., Technical report, Institute of Electrical and Electronics Engineers.

J. A Pomilio, S. D. (1995). Efeito flicker produzido pela modulacao harmonica, Seminario Brasileiro de Qualidade da Energia Eletrica .

Microship (2017). Microship PIC18F2455/2550/4455/4550 Data Sheet.

MicroSystems, A. (2017). Data sheet acs 712 fully integrated, hall effect-based linear current sensor ic with 2.1 kvrms isolation and a low-resistance current conductor.

Shilpa.R, P. (2014). A review on power quality issues in power systems, International Journal of Industrial Electronics and Electrical Engineering 02.

T. Radil, P. M. Ramos, F. M. J. A. C. S. (2007). Dsp based power quality analyzer for detection and classification of disturbances in a single-phase power system, Metrology And Measurement Systems 14.

Teixeira, D. (2009). Analise das distorcoes harmonicas: Estudo de caso de um sistema industrial, Master's thesis, Universidade Federal de Minas Gerais. 